Seutloali, K.E. et al. (2018). Developments in the remote sensing of soil erosion in the perspective of sub-Saharan Africa. Implications on future food security and biodiversity. Remote Sensing Applications: Society and Environment, 9: 100-106.

\title{
Developments in the remote sensing of soil erosion in the perspective of sub-Saharan Africa. Implications on future food security and biodiversity
}

Khoboso E. Seutloali, Timothy Dube and Mbulisi Sibanda

\begin{abstract}
The remote sensing of soil erosion has gained substantial consideration, with considerable scientific research work having been conducted in the past, due to technological improvements that have resulted in the release of robust, cheap and high resolution datasets with a global foot-print. This paper reviews developments in the application of remote sensing technologies in sub-Saharan Africa with a explicit emphasis on soil erosion monitoring. Soil loss due to soil erosion by water has been identified by African geomorphologists, environmentalists and governments, as the primary threat to agriculture, biodiversity and food security across the continent. The article offers a detailed review of the progress in the remote sensing as it summarises research work that have been conducted, using various remote sensing sensors and platforms and further evaluates the significance of variations in sensor resolutions and data availability for sub-Saharan Africa. Explicit application examples are used to highlight and outline this progress. Although some progress has been made, this review has revealed the necessity for further remote sensing work to provide time-series soil erosion modelling and its implications on future food security and biodiversity in the face of changing climate and food insecurity. Overall, this review have shown the immediate need for a drastical move towards the use of new generation sensors with a plausible spatial, temporal characteristics and more importantly a global foot-print.
\end{abstract}

\section{Introduction}

Soil erosion is a critical environmental degradation problem globally (Ananda and Herath, 2003; Gobin et al., 2004; Pimentel, 2006; Yang et al., 2003; Ma et al., 2014; SchönbrodtStitt et al., 2013; Seutloali and Beckedahl, 2015a). This is due to its adverse impacts on agricultural production, water quality, soil resources and hydrological systems which pose a problem to human sustainability (Chen et al., 2011). Soil erosion is predominantly high in Africa, Asia and South America, with an average soil loss of 30-40 t ha ${ }^{-1}$ year ${ }^{-1}$ (Ananda and Herath, 2003). For instance, each year, about $5 \mathrm{Mg} \mathrm{ha}^{-1}$ of productive topsoil is removed in Africa, due to this environmental scourge (Angima et al., 2003). In sub-Saharan africa, approximately 360 Mha of land is currently experiencing serious soil erosion risk (Vaggen et al., 
2005), and this has far reaching environmental, social, political and economic implications, which results either onsite or offsite damages (Chen et al., 2011; Dabral et al., 2008). For instance, severe soil erosion that has been documented in the sub-Saharan Africa has resulted in declining soil fertility, ultimately affecting poverty and food security (Cohen et al., 2006). Mapping and monitoring the magnitude and spatial distribution of soil erosion is therefore an important technical task if sustainable land management is to be achieved (Alejandro and Omasa, 2007; Jain and Das, 2010; Le Roux et al., 2007). It is therefore crucial to have up to-date spatial information about the magnitude and extent of soil erosion for soil conservation planning and land rehabilitation programme (Aydda et al., 2014; Baban and Yusof, 2001; Lo Curzio and Magliulo, 2010), particularly in regions, such as the sub-Saharan Africa where livelihoods depend on soil quality for agricultural production.

The recognition of soil erosion by water as a serious environmental problem worldwide including the sub-Saharan Africa, has resulted in the development of several soil erosion assessment methods. The first approach includes field measurements of soil erosion rates, such as the use of erosion plots based on natural or simulated rainfall (Boix-Fayos et al., 2007; Cerdan et al., 2010; Nearing et al., 1999). However, these methods are limited to specific erosion factor assessment, model development and validation (Vrieling, 2006). Moreover, these models do not account for the spatial distribution of erosion activities, as they are limited to small spatial extents. The second approach includes field survey techniques that involve the identification and qualitative or quantitative evaluation of erosion features (Beckedahl and De Villiers, 2000; Sidle et al., 2011). This approach however, allows a small spatial scale mapping of erosion features, such as small catchments making it difficult to map larger areas, besides being labour intensive, costly, time-consuming and sometimes inapplicable, due to poor accessibility of eroded sites (Niemiec, 2009). Similarly, Le Roux et al. (2007) further indicate that these conventional methods provide data limited to local conditions and do not provide broad input datasets for soil erosion monitoring at regional scale. The third approach is the estimation of soil loss, through the use of soil erosion prediction models. This method is a quantitative process for soil loss estimation,through the integration of spatial data on erosion factors (Niemiec, 2009). The soil erosion prediction models however, require a series of detailed datasets on input parameters, such as soil, slope, vegetation and rainfall amongst others (Seutloali and Beckedahl, 2015b).

Although the above mentioned approaches provide necessary information for soil erosion assessment and accounting, they however, depend on expensive, time consuming and labour intensive onsite sampling and data collection and this makes them limited in temporal and spatial scales to address soil erosion at larger scales (i.e. regional or national scales). In resource-scarce regions, such as the sub-Saharan Africa, distribution of already strained financial resources for conservation and rehabilitation purposes, as well as the development of policies and regulations; necessitates soil erosion assessment at a regional scale in order to divert resources on limited areas (Vrieling et al., 2006). However, good quality spatial data on soil erosion remains a challenge, especially the sub-Saharan Africa (Vrieling, 2006). For instance, Le Roux et al. (2007) indicates that the derived data from soil erosion observations around South Africa is limited to local conditions and that it does 
not provide adequate input datasets for soil loss monitoring at regional scales. Meanwhile, remote sensing offers a practical and economical means to evaluate and monitor soil erosion at a regional scale and can make field sampling more focused and efficient (King et al., 2005; Lo Curzio and Magliulo, 2010; Lu et al., 2004; Wang et al., 2003). Its high temporal coverage offers archive data for assessing the dynamics of soil erosion change over time and space (Vrieling, 2006), and its digital data can be easily integrated into Geographic Information System (GIS) for further analysis (Saini et al., 2015). In the light of these advantages, researchers have used remote sensing techniques to identify soil erosion features, discriminate eroded areas and assess soil erosion intensity based on empirical relations between erosion sites and remotely sensed data (Vrieling, 2006).

The rapid increase in the number of studies that have used remote sensing in studying soil erosion worldwide makes it imperative to provide an overview of the extent to which the technology has been used in an African context. This information is useful for land management, crafting robust land rehabilitation measures and in identifying optimal and cheap satellite data that can derive accurate information on various levels of soil erosion at regional scale. The prevalent levels of land degradation and the economic situation in most countries of sub-Saharan Africa necessitates cost effective and accurate methods for rapid, accurate and efficient soil erosion evaluation at regional scales. This article therefore seeks to review the status of the application of remote sensing in soil erosion assessment and monitoring in sub-Saharan Africa with special focus on: (i) methods used to assess and monitor erosion using remotely sensed data; (ii) overview of the most applied remote sensing datasets in sub-Saharan Africa and the highlighted reasons for the choice of the datasets; and (iii) highlighting the major capabilities and challenges of using remotely sensed data to evaluate soil erosion in sub-Saharan Africa.

\section{Remote sensing applications in soil erosion monitoring}

Soil erosion mapping using remotely sensed data has been historically based on the visual interpretation of aerial photography (e.g. Morgan et al., 1980; Nachtergaele and Poesen, 1999; Morgan et al., 1978; Thomas et al., 1986). These studies concluded that aerial photographs are a viable alternative data source, providing detailed soil erosion information. This is because of the provision of high quality data that was deemed to be in agreement with data obtained from other erosion prediction methods. However, it is not feasible to utilise aerial photographs for continous mapping and monitoring of soil erosion at a landscape scales. This is because aerial photographs are costly and time consuming to process. Satellite remote sensing has therefore increased the ability to map and monitor soil erosion up to regional scales i.e. national scale (Le Roux et al., 2007; Pan and Wen, 2014; Panagos et al., 2015). Various satellite remote sensing techniques have been employed for mapping and monitoring soil erosion at different levels. When using remotely sensed data, erosion can be detected based on the correlation between erosion and spectral reflectance values (Le Roux et al., 2007; Vrieling, 2006). For instance, Haboudane et al. (2002) successfully mapped the spatial distribution of regional patterns of soil erosion in the Guadalentin basin, south eastern Spain, using specteral mixture analysis and a set of indices. They stressed that the soil surface optical properties can be utilised as indicators 
of erosion in semi-arid environments. They also noted that indices incorporating shortwave infrared bands are effective in identifying pedogenetic indicators and erosion in sparsely vegetated areas.

Besides the direct correlation between soil erosion and varying spectral reflectances, automatic extraction including supervised and unsupervised classification using techniques, such as the maximum likelihood and principle component techniques has also successfully been utilised in soil erosion detection and mapping (Le Roux et al., 2007). Alatorre and Beguería (2009) applied a supervised classification method using the maximum likelihood algorithm to identify eroded areas in a badlands landscape on marls in the central Spanish Pyrenees. This method enabled the discrimination of heavily eroded lands from sparse and densely vegetated areas, based on the spectral signature of bare soil on marls. Similarly, Vrieling et al. (2007) accurately identified erosion gullies in the Brazilian Cerrados from ASTER imagery, using a maximum likelihood classification. They concluded that a similar methodology may be applied to images obtained by different satellites, such as SPOT-5 and Landsat TM and ETM+ amongst others.

Detection of offsite effects of soil erosion, such as sediment deposition and dissolved sediments in waterbodies can also supply information on soil erosion intensity (Jain and Das, 2010; Jain et al., 2002). Jain et al. (2002) assessed sediment deposition in the Bhakra reservoir situated along Satluj River in the foothills of the Himalayas using satellite datasets (IRS-IB, LISS II) and found that the results obtained from this approach were comparable to those obtained from the hydrographic survey. Similarly Miller and McKee (2004) utilised MODIS $250 \mathrm{~m}$ data to map the concentration of Total Suspended Sediments of coastal waters in the Northern Gulf of Mexico to determine transport and fate of eroded material. A short revisit period (i.e. near-daily) of MODIS instrument allowed an analysis of a significant short-term changes in the horizontal sediment trail. Moreover, a linear relationship was found between MODIS $(250 \mathrm{~m})$ Band $1(620-670 \mathrm{~nm})$ data and field measurements of Total Suspended Sediments. Goel et al. (2002) successfully assessed sediment deposition rate in Bargi Reservoir in India, using the IRS-1C multispectral satellite data, LLIS-III sensor and concluded that remote sensing techniques provide a timely, cost effective and convenient approach to estimate reservoir sedimentation as a proxy for soil erosion activities.

Repeat-pass Synthetic aperture radar (SAR) interferometry enables detection of the change in soil erosion (Vrieling, 2006). SAR interferometry allows high-resolution measurements of topography, as well as surface deformation (Massonnet and Feigl, 1998). Smith et al. (2000) utilised SAR interferometry data to assess the distribution of erosion and deposition volume on the Skeidararsandur, Iceland following a flood event. In this study, disturbed and preserved surfaces were identified by their effect on interferometric phase correlation and the net topographic change was estimated by correcting and differencing interferometric topography before and after the flood. 
Eroded surfaces can be mapped through on screen visual interpretation techniques of satellite images, based on differing spectral properties (Le Roux et al., 2007). For example, Dwivedi et al. (1997b) successfully interpreted Landsat MSS, TM and Indian Remote Sensing Satellite (IRS-1A) Linear Imaging Self-scanning Sensor (LISS-II) to derive qualitative information on eroded lands in a rugged terrain. They concluded that the finer spatial remote sensing datasets allow mapping at larger scales due to provision of terrain features which can be utilised in conjunction with ancillary data and ground information to obtain information on eroded lands. Similarly, erosion risk can be determined from utilising vegetation and topographic characteristics, acquired from additional data sources (Jain and Das, 2010; Vrieling, 2006). For instance Seutloali et al. (2015) utilised slope gradient calculated from the free-and-readily available 30-m spatial resolution Advanced Spaceborne Thermal Emission and Reflection Radiometer (ASTER) Global Digital Elevation Model (GDEM) to find out whether they could explain the morphology of gullies. The study concluded that the use of ancillary data or satellite derivatives, such as digital elevation models, improves soil erosion assessment.

Fine spatial resolution remotely sensed data from platforms such as unmanned aerial vehicles has also been utilised in effectively mapping soil erosion activities. Peter et al. (2014) used unmanned aerial vehicle (UAV) remote sensing data in conjunction with experimental rainfall simulations in mapping gullies in the Souss valley of South Morocco. Their quantification of soil erosion by UAV data illustrated that a gully in a levelled study site eroded about $720 \mathrm{~m} 3$ of soil within a single rain period.

\section{General overview of remote sensing application in soil erosion}

In the recent decades, soil erosion research community has shown an intense interest in soil erosion assessment and monitoring, particularly in sub-Saharan Africa. This is because land degradation is increasing at faster rates while removing the top soil required for food productivity. The main goal is to create mechanisms that could be used to detect, monitor erosion activities so as to come up with effective site-specific soil erosion control methods, as well as propose rehabilitation solutions for degraded lands. Several remote sensing datasets, ranging from coarse, medium and fine spatial and spectral resolution satellite data, as well as image-derived products such as Digital elevation models (DEM) have been utilised in the subSaharan Africa to assess and monitor soil erosion. A sample of studies that have used these datasets together with the findings and conclusions of each study is given in Table 1.

\subsection{Coarse resolution sensors}

Coarse resolution has been defined by Xie et al. (2008) as pixels with ground sampling distance greater or equal to $30 \mathrm{~m}$. Coarse resolution satellite data (e.g. Very High Resolution Radiometer (AVHRR) of the National Oceanic and Atmospheric Administration (NOAA) satellites, Medium Resolution Imaging Spectrometer (MERIS) and Moderate Resolution Imaging Spectroradiometer (MODIS)) have most frequently been utilised in soil erosion research in many parts of the world. These datasets have been primarily utilised to evaluate the spatial distribution of vegetation cover, estimated suing the normalised difference vegetation 
index (NDVI) and the Leaf area Index (LAI), as proxies for assessing the spatial distribution of soil erosion. Le Roux et al. (2008) utilised MODIS datasets to determine NDVI for soil erosion prediction at a national scale in South Africa. In southern Africa however, the application of course resolution datasets has been widely used to monitor vegetation productivity to asssess land degradation (e.g. Wessels et al., 2004; Thiam, 2003; Wessels et al., 2008; Mbow et al., 2015; Diouf and Lambin, 2001; Davis et al., 2017; Ibrahim et al., 2015). Most studies utilising coarse resolution data have been conducted elsewhere. For instance, Garatuza-Payán et al. (2005) successfully estimated temporal variability in potential soil loss in Yaqui river basin, located in northwest of Mexico and southwest USA, using NDVI derived from NOAA-AVHRR data. In their study conducted for the European continent, Panagos et al. (2014) concluded that the free and readily-available MODIS datasets have a potential of being used in environmental models, such as those dealing with soil erosion. Moreover, they demonstrated that products derived from MODIS improve both the spatial and temporal monitoring of biophysical characteristics of vegetation across large geographical areas, such as continents. Panagos et al. (2012) successfully derived LAI from Medium resolution imaging spectrometer (MERIS) data to use in the development of an erosion model and its application in the Strymonas catchment area, located in the cross border between Greece and Bulgaria. Although coarse resolution datasets have a lower spatial resolution, when compared to other spatial resolutions, they offer near daily spatial data at a high temporal resolution, which is suitable for perpetual monitoring and management of soil erosion activities (Millington and Townshend, 1984; Wessels et al., 2004; Ibrahim et al., 2015). Vrieling et al. (2008) suggested that the combination of these datasets with medium resolution data provides a potential for effective mapping of vegetation in regions where vegetation cover greatly varies spatially and temporally. Moreover, the use of coarse resolution datasets could possibly direct attention to regions where high resolution datasets are required (Wessels et al., 2004).

\subsection{Medium resolution sensors}

Medium resolution datasets provide multispectral surface information on a regional scale and can be used for a range of applications. For instance, these satellite datasets have been used particularly for change detection, due to their availability for approximately three decades (Kuenzer et al., 2011). Literature shows that medium resolution data-sets, such as Landsat TM and ETM, Systeme Pour l'Observation de la Terre (SPOT) and Advanced Spaceborne Thermal Emission and Reflection Radiometer (ASTER) have been used in soil erosion assessment and monitoring in the Sub-Saharan Africa region. Fadul et al. (1999) successfully utilised Landsat TM for mapping gully erosion across different land uses, topography and drainage patterns along the Atbara River in Sudan. In their study in the Monduli District, northern Tanzania, Kiunsi and Meadows (2006) indicated that the use of Landsat TM datasets allows soil erosion detection and mapping at a cheaper cost than other satellite datasets (e.g. SPOT 5) and at larger scale. However, other studies, such as that of Le Roux and Sumner (2012), who mapped gully erosion for a catchment located in the Eastern Cape Province, South Africa, using SPOT 5 satellite data, indicated that panchromatic bands of SPOT 5 have the capability of detecting and mapping gullies at catchment scale with higher accuracy. The advantage of using Landsat datasets for soil erosion detection and mapping in sub-Saharan Africa, however, is the ability to 
acquire these datasets at a cheaper or no cost, particularly in resource-scarce regions. Moreover, Landsat imagery was launched in the 1970 allowing soil erosion mapping over a long period of time which enables change detection of soil erosion development (Taruvinga, 2009). Hence, these datasets have been predominantly used across sub-Saharan Africa, for soil erosion studies (e.g. Fadul et al., 1999, Kiunsi and Meadows, 2006, Taruvinga, 2009, Vrieling et al., 2006).

\subsection{High resolution sensors}

Literature shows that high resolution datasets, such as QuikBird and IKONOS are available for soil erosion detection and monitoring. In addition to their ability to identify individual gullies, these datasets can provide subtle information on smaller erosion features, such as rills as well as signs of overland flow (Vrieling et al., 2008). Since, it is not yet possible to automatically retrieve individual erosion features, due to high spectral heterogeneity within a feature class, as well as the environment in general (Le Roux et al., 2007), high accuracy is attained through manual digitising. However, manual digitising is subjective particularly during on-screen interpretations, it is laborious and time consuming which makes the repetition of such a study cumbersome. Furthermore, the fine spatial images are expensive for soil erosion detection at large scale (Mararakanye and Nethengwe, 2012). Similarly, Vrieling et al. (2008), also stated that these datasets are very expensive to acquire, particularly for mapping gullies in large areas. Hence, high resolution datasets may not be affordable for developing countries, such as those in the sub-Sahara Africa, and their use for identifying erosion features has not yet been reported in the literature (Le Roux et al., 2007). 


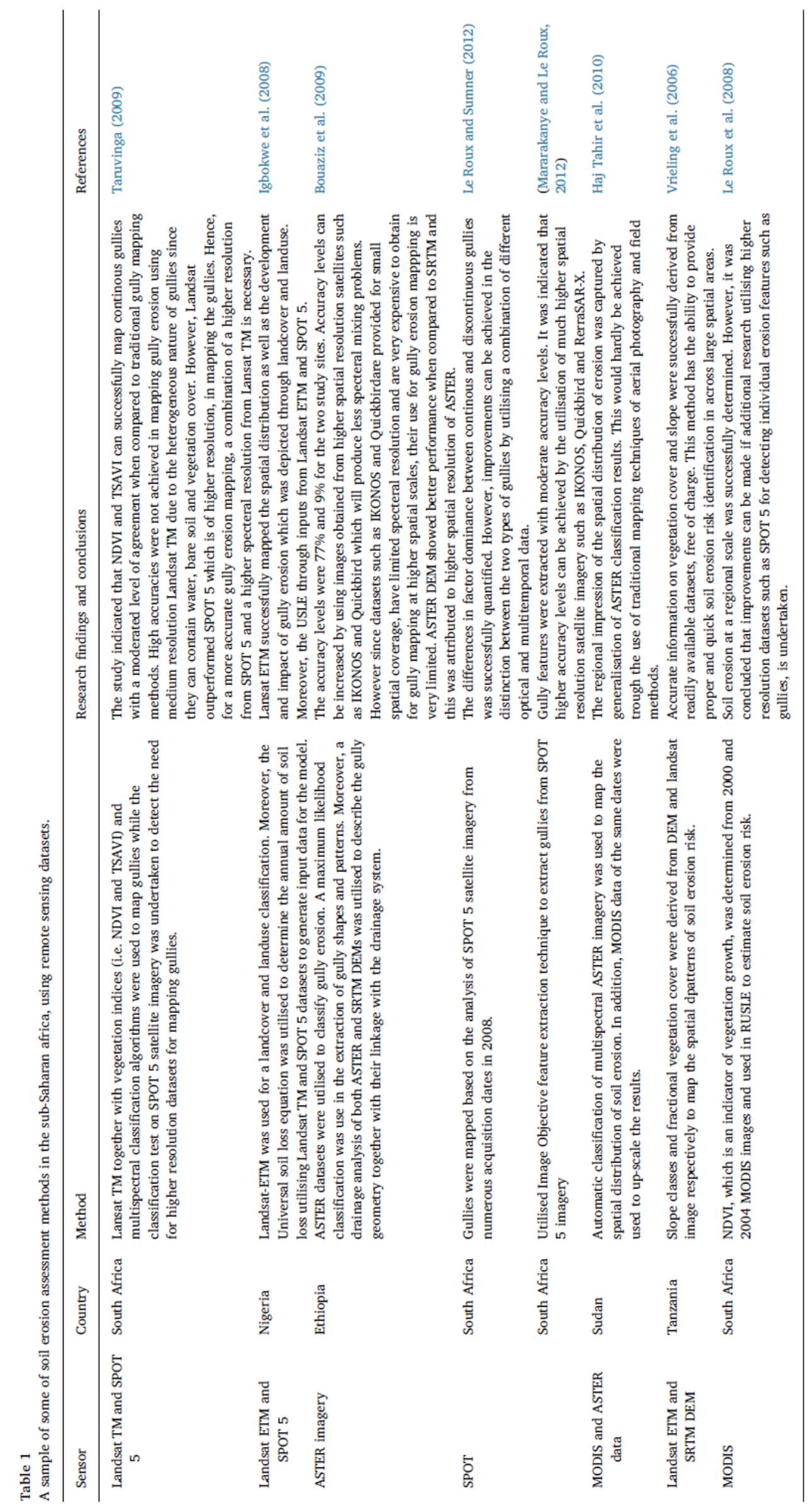




\subsection{Digital elevation models}

The use of ancillary data or satellite derivatives, such as digital elevation models has been shown to improve soil erosion assessment and monitoring. DEM are frequently being used in conjunction with geographic information system (GIS) tools for determining topographic variables in soil erosion studies in sub-Saharan Africa. For example, Mati et al. (2000) assessed soil erosion hazard in the Upper Ewaso Ng'iro North basin of Kenya based on Universal Soil Loss Equation and DEM data to topographic factor $(L S)$. Similarly, Daba et al. (2003) successfully predicted hillslope areas that were vulnerable to gully erosion in eastern Ethiopia based on the topographic variables (contributing area and slope) derived from a DEM. Several satellite datasets are available for extraction of DEMs and these include the stereo optical imagery provided by ASTER and SPOT (Toutin and Gray, 2000). DEM provided by the ASTER Shuttle Radar Topography Mission (SRTM) are however, the mostly widely used DEMs. This is due to their high spatial resolution, as well as their free availability at limited costs (Toutin and Cheng, 2002) especially to resource scarce regions, such as the sub-Saharan Africa. For instance, Seutloali et al. (2016) used Advanced Spaceborne Thermal Emission and Reflection Radiometer (ASTER) Global Digital Elevation Model (GDEM) to extract the hillslope gradient for determining the conditions for soil erosion development along major roads in the South eastern region of South Africa. They stressed the importance of these datasets in erosion studies, particularly in Africa where field methods are expensive.

\section{Capabilities and limitations of sensors currently utilised in mapping soil erosion}

There has been considerable progress in the application of remote sensing techniques in soil erosion research. Remote sensing techniques could play a vital role in detecting and mapping areas that have been affected by different forms and intensities of soil erosion. Hence, the use of remote sensing to detect and map soil erosion across sub-Saharan Africa has gained attention in the last decade. While several studies have successfully utilised remote sensed data in soil erosion research, there are still challenges that still need to be addressed. For instance soil erosion mapping has primarily been based on the use of vegetation indices derived from satellite imagery (e.g. Le Roux et al., 2008; Taruvinga, 2009; Sun et al., 2014). The heterogeneity of erosion features, such as gullies, however, deems vegetation indices inappropriate for mapping gully erosion.

A few satellite datasets can be applied for direct soil erosion detection and monitoring. For instance, there has been advances in developed regions for a direct soil erosion assessment using high resolution datasets. However, the sub-Saharan regions still face challenges in acquiring such datasets. Higher costs associated with high resolution datasets have limited

their use in soil erosion assessment in the sub-Saharan Africa. For example, high resolution datasets, such as IKONOS and Quickbird are expensive and not readily accessible (Vrieling et al., 2008) and this is a challenge in resource-scarce regions. There is, therefore, a handful of studies that have used these datasets in the African context. In addition, it has been indicated by (Le Roux et al., 2007) that their use in soil erosion research has not yet been 
reported in the literature. Moreover, where fine spatial resolution data are utilised, their applications are limited by their associated costs to small/local scales (Bouaziz et al., 2009). This becomes a challenge, particularly in the sub-Saharan Africa context, where soil erosion information covering large spatial scales is urgently required for soil conservation, planning and land rehabilitation programmes.

The Newly launched Sentinel 2 multispectral imager (MSI) could therefore be another alternative for the above mentioned fine spatial resolution sensors. Sentinel-2 MSI covers the red-edge spectral region and a relatively finer spatial resolutions (i.e. 10, 20 and $60 \mathrm{~m}$ ), which could be critical in detecting soil erosion activities directly and indirectly through vegetation cover and other proxies. Furthermore, Sentinel -MSI is freely available for applications such as assessing and monitoring soil erosion activities. This dataset has been successfully applied in vegetation related studies. For a example, the study by Sibanda et al. (2015) demonstrated that the Sentinel 2 MSI data is more robust in estimating grass biomass when compared to traditional multispectral data such as Landsat series data. These sample studies therefore provide an insight into the prospects of erosion modelling and mapping, using the newly launched, cheap and readily available multispectral data.

Most studies that have been conducted to assess soil erosion in the sub-Saharan Africa have been based on medium resolution imagery, such as Landsat and ASTER (e.g. Bouaziz et al., 2009; Haj Tahir et al., 2010; Igbokwe et al., 2008; Taruvinga, 2009; Vrieling et al., 2006). Literature has already indicated that these medium resolution datasets have the greatest potential for detecting and mapping soil erosion in the sub-Saharan Africa (Taruvinga, 2009), due to their affordability and the associated global-foot print. Landsat series data offers spatial data with a global foot-print dating back to the several years, it has a swath width of $185 \mathrm{~km}$ suitable for regional to landscape scale erosion mapping applications. Furthermore, the newly launched Landsat 8 operational land imager (OLI) offers even improved remotely sensed data characterised by high signal-to-noise ratios associated with its push broom scanner technology (Dube and Mutanga, 2015).

Above all, Landsat data is freely available for utilisation in applications such estimating soil erosion activities, which commonly occurs at a regional scale. Moreover, although characterised by moderate spatial resolutions, these datasets have satisfactory spectral resolutions. Consequently, these dataset are often used in combination with higher spatial resolution, such as SPOT 5 to provide high accuracies in estimating erosion activities at larger scales (Taruvinga, 2009). Remote sensing technology has therefore remained useful in the sub-Saharan Africa, particularly for regional evaluation, and hence serve as a significant basis for detecting areas where soil conservation and rehabilitation should focus on.

\section{Implications of mapping soil erosion on biodiversity and future food security}

Literature indicates that about 10 million hectares of cropland is lost though soil erosion annually thereby drastically reducing the croplands that are critical for food production (Pimentel, 2006). Furthermore, the World Health Organization reported that above 3.7 
billion people are malnourished in the world partly due to soil erosion of arable croplands and climate change related issues. Subsequently, up to-date spatially explicit information on the magnitude and extent of soil erosion is urgently required and it is critical for site-specific soil conservation planning and land rehabilitation programme (Aydda et al., 2014; Baban and Yusof, 2001; Lo Curzio and Magliulo, 2010). The lack of spatially explicit information on arable land soil erosion and malnourishment are more pronounced in regions such as the sub-Saharan Africa, where livelihoods depend on soil quality for agricultural production. Moreover, the loss of soils from arable land areas is 10-40 times faster than the rate of soil renewal endangering future human food security and environmental resources (Pimentel, 2006). In that regard, spatial data is urgently required for supporting policy development and action for future food security as well as biodiversity conservation. Although improved spectral, spatial and temporal resolution data is not readily available in the sub-Saharan Africa, the recent developments in the use of these high resolution datasets could provide significant potential for effective soil erosion detection and mapping that could assist in ensuring food security.

\section{Conclusions}

This study sought to assess the status of remote sensing applications in soil erosion assessment and monitoring in sub-Saharan Africa. Literature indicates that soil erosion in the sub-Saharan Africa has resulted in a decline in the soil's functional capacity, which has cascaded to food production and insecurity regionally. Based on the findings of this review we conclude that:

- remote sensing is an ideal method for a timely investigation of soil erosion over large areas where intensive field techniques continue to be a challenge.

- traditional methods are not suitable for detecting and mapping soil erosion at larger spatial scales, due to limited resources, such as finances, skilled personnel and time medium resolution satellite data are the most utilised in detecting and mapping soil erosion in the sub-Saharan Africa environments.

- $\quad$ Although high resolution datasets provide higher accuracies and are more reliable and robust for soil erosion assessment, they are still not operational in the sub-Saharan Africa environment, owing to the high acquisition cost. Due to financial constraints, in most of the countries in sub-Saharan Africa, medium resolution datasets are the only significant source of spatial information suitable for soil erosion assessment.

There is, therefore, a need for more information on the spatial distribution, the magnitude, as well as intensity of soil erosion in sub-Saharan Africa for proper soil conservation and rehabilitation practices. In addition, there is a need for more robust methods that can be used to assess soil erosion at larger spatial scales in a timely manner and at a lower or no cost. It is therefore necessary for future studies to investigate the applicability of these datasets in detecting and mapping the intensity and magnitude of soil erosion, particularly at regional scales. Future studies need to evaluate the integration of high spatial resolution datasets with moderate to coarse resolutions, in oder to improve the accuracy of estimating and mapping the extent and occurrence of soil erosion. The utility of the newly 
launched and the forthcoming sensors that are going to offer spatial data with limited costs and at high spectral resolutions, such as the HyspIRI and Hymapper have to be evaluated in mapping erosion activities in future. 


\section{References}

Alatorre, L., Beguería, S., 2009. Identification of eroded areas using remote sensing in a badlands landscape on marls in the central Spanish Pyrenees. Catena 76, 182-190.

Alejandro, M., Omasa, K., 2007. Estimation of vegetation parameter for modeling soil erosion using linear spectral mixture analysis of Landsat ETM data. ISPRS J. Photogramm. Remote Sens. 62, 309-324.

Ananda, J., Herath, G., 2003. Soil erosion in developing countries: a socio-economic appraisal. J. Environ. Manag. 68, 343-353.

Angima, S., Stott, D., O’Neill, M., Ong, C., Weesies, G., 2003. Soil erosion prediction using RUSLE for central Kenyan highland conditions. Agric. Ecosyst. Environ. 97, $295-308$.

Aydda, A., Ah, A., Ab, A., Essemani, M., Taghya, Y., 2014. A new method to determine eroded areas in arid environment using Landsat satellite imagery. IOP Conf. Ser.: Earth Environ. Sci. 012021 (IOP Publishing).

Baban, S.M., Yusof, K.W., 2001. Modelling soil erosion in tropical environments using remote sensing and geographical information systems. Hydrol. Sci. J. 46, 191-198.

Beckedahl, H., De Villiers, A., 2000. Accelerated erosion by piping in the Eastern Cape Province, South Africa. South Afr. Geogr. J. 82, 157-162.

Boix-Fayos, C., Martínez-Mena, M., Calvo-Cases, A., Arnau-Rosalén, E., Albaladejo, J., Castillo, V., 2007. Causes and underlying processes of measurement variability in field erosion plots in Mediterranean conditions. Earth Surf. Process. Landf. 32, 85101.

Bouaziz, M., Wijaya, A., Gloaguen, R., 2009. Gully erosion mapping using ASTER data and drainage network analysis in the main ETHIOPIAN rift. IGARSS (1), 13-16.

Cerdan, O., Govers, G., Le Bissonnais, Y., Van Oost, K., Poesen, J., Saby, N., Gobin, A., Vacca, A., Quinton, J., Auerswald, K., 2010. Rates and spatial variations of soil erosion in Europe: a study based on erosion plot data. Geomorphology 122, 167177.

Chen, T., Niu, R.-Q., Li, P.-X., Zhang, L.-P., Du, B., 2011. Regional soil erosion risk mapping using RUSLE, GIS, and remote sensing: a case study in Miyun Watershed, North China. Environ. Earth Sci. 63, 533-541.

Cohen, M.J., Brown, M.T., Shepherd, K.D., 2006. Estimating the environmental costs of soil erosion at multiple scales in Kenya using emergy synthesis. Agric. Ecosyst. Environ. 114, 249-269.

Daba, S., Rieger, W., Strauss, P., 2003. Assessment of gully erosion in eastern Ethiopia using photogrammetric techniques. Catena 50, 273-291.

Dabral, P., Baithuri, N., Pandey, A., 2008. Soil erosion assessment in a hilly catchment of North Eastern India using USLE, GIS and remote sensing. Water Resour. Manag. 22, $1783-1798$.

Davis, C., Hoffman, M., Roberts, W., 2017. Long-term trends in vegetation phenology and productivity over Namaqualand using the GIMMS AVHRR NDVI3g data from 1982 to 2011. South Afr. J. Bot. 111, 76-85.

Dube, T., Mutanga, O., 2015. Investigating the robustness of the new Landsat-8 Operational Land Imager derived texture metrics in estimating plantation forest aboveground 
biomass in resource constrained areas. ISPRS J. Photogrammetry Remote Sens. 108, $12-32$.

Diouf, A., Lambin, E., 2001. Monitoring land-cover changes in semi-arid regions: remote sensing data and field observations in the Ferlo, Senegal. J. Arid Environ. 48, 129148.

Fadul, H.M., Salih, A.A., Imad-Eldin, A.A., Inanaga, S., 1999. Use of remote sensing to map gully erosion along the Atbara River, Sudan. Int. J. Appl. Earth Obs. Geoinf. 1, 175180.

Garatuza-Payán, J., Sánchez-Andrés, R., Sánchez-Carrillo, S., Navarro, J.M., 2005. Using remote sensing to investigate erosion rate variability in a semiarid watershed, due to changes in vegetation cover. IAHS Publ. 292, 144-151.

Dwivedi, R.S., Sankar, T.R., Venkaratnam, L., Karale, R.L., Gawande, S.P., Rao, K.V.S., Senchaudhary, S., Bhaumik, K.R., Mukharjee, K.K., 1997b. The inventory and monitoring of eroded lands using remotesensing data. Int. J. Remote Sens. 18 (1), 107-119.

Gobin, A., Jones, R., Kirkby, M., Campling, P., Govers, G., Kosmas, C., Gentile, A., 2004. Indicators for pan-European assessment and monitoring of soil erosion by water. Environ. Sci. Policy 7, 25-38.

Goel, M., Jain, S.K., Agarwal, P., 2002. Assessment of sediment deposition rate in Bargi Reservoir using digital image processing. Hydrol. Sci. J. 47, S81-S92.

Haboudane, D., Bonn, F., Royer, A., Sommer, S., Mehl, W., 2002. Land degradation and erosion risk mapping by fusion of spectrally-based information and digital geomorphometric attributes. Int. J. Remote Sens. 23, 3795-3820.

Haj Tahir, M.E., Kääb, A., Xu, C.-Y., 2010. Identification and mapping of soil erosion areas in the blue Nile, Eastern Sudan using multispectral ASTER and MODIS satellite data and the SRTM elevation model. Hydrol. Earth Syst. Sci. 14, 1167-1178.

Ibrahim, Y.Z., Balzter, H., Kaduk, J., Tucker, C.J., 2015. Land degradation assessment using residual trend analysis of GIMMS NDVI3g, soil moisture and rainfall in Sub-Saharan West Africa from 1982 to 2012. Remote Sens. 7, 5471-5494.

Igbokwe, J., Akinyede, J., Dang, B., Alaga, T., Ono, M., Nnodu, V., Anike, L., 2008. Mapping and monitoring of the impact of gully erosion in southeastern Nigeria with satellite remote sensing and geographic information system. Int. Arch. Photogramm. Remote Sens. Spat. Inf. Sci. 37, B8.

Jain, M.K., Das, D., 2010. Estimation of sediment yield and areas of soil erosion and deposition for watershed prioritization using GIS and remote sensing. Water Resour. Manag. 24, 2091-2112.

Jain, S.K., Singh, P., Seth, S., 2002. Assessment of sedimentation in Bhakra Reservoir in the western Himalayan region using remotely sensed data. Hydrol. Sci. J. 47, $203-212$.

King, C., Baghdadi, N., Lecomte, V., Cerdan, O., 2005. The application of remote-sensing data to monitoring and modelling of soil erosion. Catena 62, 79-93.

Kiunsi, R., Meadows, M., 2006. Assessing land degradation in the Monduli district, northern Tanzania. Land Degrad. Dev. 17, 509-525.

Kuenzer, C., Bluemel, A., Gebhardt, S., Quoc, T.V., Dech, S., 2011. Remote sensing of mangrove ecosystems: a review. Remote Sens. 3, 878-928. 
Le Roux, J., Morgenthal, T., Malherbe, J., Pretorius, D., Sumner, P., 2008. Water erosion prediction at a national scale for South Africa. Water SA 34, 305-314.

Le Roux, J.J., Newby, T., Sumner, P., 2007. Monitoring soil erosion in South Africa at a regional scale: review and recommendations. South Afr. J. Sci. 103, 329-335.

Le Roux, J.J., Sumner, P., 2012. Factors controlling gully development: comparing continuous and discontinuous gullies. Land Degrad. Dev. 23, 440-449.

Lo Curzio, S., Magliulo, P., 2010. Soil erosion assessment using geomorphological remote sensing techniques: an example from southern Italy. Earth Surf. Process. Landf. 35, 262-271.

Lu, D., Li, G., Valladares, G., Batistella, M., 2004. Mapping soil erosion risk in Rondonia, Brazilian Amazonia: using RUSLE, remote sensing and GIS. Land Degrad. Dev. 15, 499-512.

Ma, X., He, Y., Xu, J., Van Noordwijk, M., Lu, X., 2014. Spatial and poral variation in rainfall erosivity in a Himalayan watershed. Catena 121, 248

Mararakanye, N., Le Roux, J., 2012. Gully location mapping at a national scale for South Africa. South Afr. Geogr. J. 94, 208-218.

Mararakanye, N., Nethengwe, N.S., 2012. Gully features extraction using remote sensing techniques. South Afr. J. Geomat. 1, 109-118.

Massonnet, D., Feigl, K.L., 1998. Radar interferometry and its application to changes in the Earth's surface. Rev. Geophys. 36, 441-500.

Mati, B.M., Morgan, R.P., Gichuki, F.N., Quinton, J.N., Brewer, T.R., Liniger, H.P., 2000. Assessment of erosion hazard with the USLE and GIS: a case study of the Upper Ewaso Ng'iro North basin of Kenya. Int. J. Appl. Earth Obs. Geoinf. 2, 78-86.

Mbow, C., Brandt, M., Ouedraogo, I., De Leeuw, J., Marshall, M., 2015. What four decades of earth observation tell us about land degradation in the Sahel? Remote Sens. 7, 40484067.

Miller, R.L., McKee, B.A., 2004. Using MODIS Terra 250 m imagery to map concentrations of total suspended matter in coastal waters. Remote Sens. Environ. 93, 259-266.

Millington, A., Townshend, J., 1984. Remote sensing applications in African erosion and sedimentation studies. In: Challenges in African Hydrology and Water Resources, Proceedings of the Harare Symposium. IAHS-AISH Publication (International Association of Hydrological Sciences-Association internationale des sciences hydrologiques), pp. 373-384.

Morgan, K.M., Lee, G.B., Kiefer, R.W., Daniel, T., Bubenzer, G.D., Murdock, J.T., 1978. Prediction of soil loss on cropland with remote sensing [Soil erosion, sediment movement in a watershed]. J. Soil Water Conserv.

Morgan, K.M., Morris, D.R., Lee, G.B., Kiefer, R.W., Bubenzer, G., Daniel, T., 1980. Aerial photography as an aid to cropland erosion analysis. Trans. ASAE 23, 907-0909.

Nachtergaele, J., Poesen, J., 1999. Assessment of soil losses by ephemeral gully erosion using high-altitude (stereo) aerial photographs. Earth Surf. Process. Landf. 24, 693706.

Nearing, M.A., Govers, G., Darrell, N.L., 1999. Variability in soil erosion data from replica plots. Soil Sci. Soc. Am. J. 63, 1829-1835. 
Niemiec, M., 2009. Satellite remote sensing for water erosion assessment. Rocz. Geomatyki 7, 99-106.

Pan, J., Wen, Y., 2014. Estimation of soil erosion using RUSLE in Caijiamiao watershed, China. Nat. Hazards 71, 2187-2205.

Panagos, P., Borrelli, P., Meusburger, K., Alewell, C., Lugato, E., Montanarella, L., 2015. Estimating the soil erosion cover-management factor at the European scale. Land Use Policy 48, 38-50.

Panagos, P., Karydas, C., Borrelli, P., Ballabio, C., Meusburger, K., 2014. Advances in soil erosion modelling through remote sensing data availability at European scale. In: Proceedings of the Second International Conference on Remote Sensing and Geoinformation of the Environment (RSCy2014). International Society for Optics and Photonics, 92290I-92290I-10.

Panagos, P., Karydas, C.G., Gitas, I.Z., Montanarella, L., 2012. Monthly soil erosion monitoring based on remotely sensed biophysical parameters: a case study in Strymonas river basin towards a functional pan-European service. Int. J. Digit. Earth 5, 461-487.

Peter, K.D., D'oleire-Oltmanns, S., Ries, J.B., Marzolff, I., Hssaine, A.A., 2014. Soil erosion in gully catchments affected by land-levelling measures in the Souss Basin, Morocco, analysed by rainfall simulation and UAV remote sensing data. Catena 113, 24-40.

Pimentel, D., 2006. Soil erosion: a food and environmental threat. Environ. Dev. Sustain. 8, 119-137.

Saini, S.S., Jangra, R., Kaushik, S., 2015. Vulnerability assessment of soil erosion using geospatial techniques-A pilot study of upper catchment of Markanda river. Int. J. Adv. Remote Sens. GIS Geogr. 3, 9-21.

Schönbrodt-Stitt, S., Bosch, A., Behrens, T., Hartmann, H., Shi, X., Scholten, T., 2013. Approximation and spatial regionalization of rainfall erosivity based on sparse data in a mountainous catchment of the Yangtze River in Central China. Environ. Sci. Pollut. Res. 20, 6917-6933.

Seutloali, K., Beckedahl, H., 2015a. Understanding the factors influencing rill erosion on roadcuts in the south eastern region of South Africa. Solid Earth 6.

Seutloali, K.E., Beckedahl, H.R., 2015b. A review of road-related soil erosion: an assessment of causes, evaluation techniques and available control measures. Earth Sci. Res. J. 19, 73-80.

Seutloali, K.E., Beckedahl, H.R., Dube, T., Sibanda, M., 2016. An assessment of gully erosion along major armoured roads in south-eastern region of South Africa: a remote sensing and GIS approach. Geocarto Int. 31, 225-239.

Sidle, R.C., Furuichi, T., Kono, Y., 2011. Unprecedented rates of landslide and surface erosion along a newly constructed road in Yunnan, China. Nat. Hazards 57, 313-326.

Sibanda, M., Mutanga, O., Rouget, M., 2015. Examining the potential of Sentinel-2 MSI spectral resolution in quantifying above ground biomass across different fertilizer treatments. ISPRS Journal of Photogrammetry and Remote Sensing 110, 55-65.

Smith, L.C., Alsdorf, D.E., Magilligan, F.J., Gomez, B., Mertes, L.A., Smith, N.D., Garvin, J.B., 2000. Estimation of erosion, deposition, and net volumetric change caused by 
the 1996 Skeiðarársandur jökulhlaup, Iceland, from synthetic aperture radar interferometry. Water Resour. Res. 36, 1583-1594.

Sun, W., Shao, Q., Liu, J., Zhai, J., 2014. Assessing the effects of land use and topography on soil erosion on the Loess Plateau in China. Catena 121, 151-163.

Taruvinga, K., 2009. Gully Mapping Using Remote Sensing: Case Study in KwaZulu-Natal, South Africa (Master of Environmental Studies). University of Waterloo, Ontario.

Thiam, A., 2003. The causes and spatial pattern of land degradation risk in southern Mauritania using multitemporal AVHRR-NDVI imagery and field data. Land Degrad. Dev. 14, 133-142.

Thomas, A., Welch, R., Jordan, T., 1986. Quantifying concentrated-flow erosion on cropland with aerial photogrammetry. J. Soil Water Conserv. 41, 249-252.

Toutin, T., Cheng, P., 2002. Comparison of automated digital elevation model extraction results using along-track ASTER and across-track spot stereo images. Opt. Eng. 41, 2102-2106.

Toutin, T., Gray, L., 2000. State-of-the-art of elevation extraction from satellite SAR data. ISPRS J. Photogramm. Remote Sens. 55, 13-33.

Vågen, T.G., Lal, R., Singh, B., 2005. Soil carbon sequestration in sub-Saharan Africa: a review. Land Degrad. Dev. 16, 53-71.

Vrieling, A., 2006. Satellite remote sensing for water erosion assessment: a review. Catena $65,2-18$.

Vrieling, A., De Jong, S.M., Sterk, G., Rodrigues, S.C., 2008. Timing of erosion and satellite data: a multi-resolution approach to soil erosion risk mapping. Int. J. Appl. Earth Obs. Geoinf. 10, 267-281.

Vrieling, A., Rodrigues, S., Bartholomeus, H., Sterk, G., 2007. Automatic identification of erosion gullies with ASTER imagery in the Brazilian Cerrados. Int. J. Remote Sens. 28, 2723-2738.

Vrieling, A., Sterk, G., Vigiak, O., 2006. Spatial evaluation of soil erosion risk in the West Usambara Mountains, Tanzania. Land Degrad. Dev. 17, 301-319.

Wang, G., Gertner, G., Fang, S., Anderson, A.B., 2003. Mapping multiple variables for predicting soil loss by geostatistical methods with TM images and a slope map. Photogramm. Eng. Remote Sens. 69, 889-898.

Wessels, K., Prince, S., Frost, P., Van Zyl, D., 2004. Assessing the effects of human-induced land degradation in the former homelands of northern South Africa with a $1 \mathrm{~km}$ AVHRR NDVI time-series. Remote Sens. Environ. 91, 47-67.

Wessels, K., Prince, S., Reshef, I., 2008. Mapping land degradation by comparison of vegetation production to spatially derived estimates of potential production. J. Arid Environ. 72, 1940-1949.

Xie, Y., Sha, Z., Yu, M., 2008. Remote sensing imagery in vegetation mapping: a review. J. Plant Ecol. 1, 9-23.

Yang, D., Kanae, S., Oki, T., Koike, T., Musiake, K., 2003. Global potential soil n with reference to land use and climate changes. Hydrol. Process. 17, 2913 